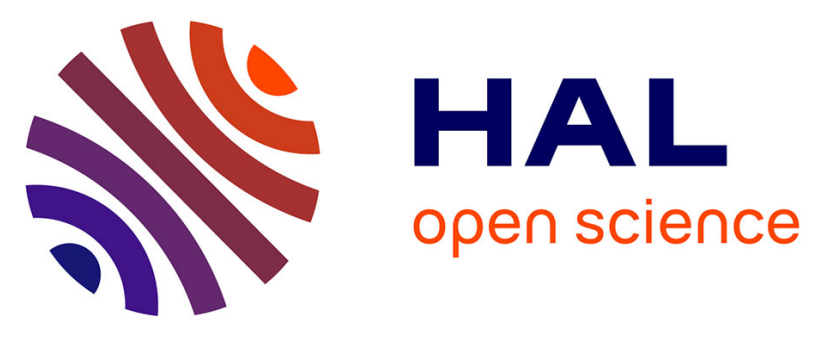

\title{
Expanded comparative mapping between man and rabbit and detection of a new conserved segment between HSA22 and OCU4
}

Céline Chantry-Darmon, Maud Bertaud, Celine C. Urien, Sead S. Chadi, M. Perrocheau, Claire Rogel Gaillard, Hélène Hayes

\section{To cite this version:}

Céline Chantry-Darmon, Maud Bertaud, Celine C. Urien, Sead S. Chadi, M. Perrocheau, et al.. Expanded comparative mapping between man and rabbit and detection of a new conserved segment between HSA22 and OCU4. Cytogenetic and Genome Research, 2005, 111, pp.134-139. hal-02672083

\section{HAL Id: hal-02672083 \\ https://hal.inrae.fr/hal-02672083}

Submitted on 31 May 2020

HAL is a multi-disciplinary open access archive for the deposit and dissemination of scientific research documents, whether they are published or not. The documents may come from teaching and research institutions in France or abroad, or from public or private research centers.
L'archive ouverte pluridisciplinaire HAL, est destinée au dépôt et à la diffusion de documents scientifiques de niveau recherche, publiés ou non, émanant des établissements d'enseignement et de recherche français ou étrangers, des laboratoires publics ou privés. 


\title{
Expanded comparative mapping between man and rabbit and detection of a new conserved segment between HSA22 and OCU4
}

\author{
C. Chantry-Darmon, ${ }^{a, b}$ M. Bertaud, a C. Urien, ${ }^{b}$ S. Chadi-Taourit, ${ }^{a}$ \\ M. Perrocheau, ${ }^{a}$ C. Rogel-Gaillard, ${ }^{b}$ H. Hayes ${ }^{a}$ \\ ${ }^{a}$ Laboratoire de Génétique biochimique et Cytogénétique, INRA; \\ ${ }^{\text {b }}$ Laboratoire de Radiobiologie et Etude du Génome, INRA CEA UMR 13.314, Jouy-en-Josas (France)
}

Manuscript received 17 December 2004; accepted in revised form for publication by H. Hameister 19 January 2005.

\begin{abstract}
Rabbit, a domestic species exploited both in animal production and medical research has only recently begun to be included in gene mapping projects, in particular by the French National Institute of Agronomics. By 2002, less than 60 genes had been precisely localised on rabbit chromosomes, which led us to start a large-scale project on gene mapping in rabbit with the publication of 133 gene localisations in 2003
\end{abstract}

(Chantry-Darmon et al., 2003). Here, we report the localisation of 102 new genes resulting in good coverage of the rabbit genome and an eight-fold enrichment of the gene map. In addition, we have detected a new conserved segment between rabbit chromosome 4q15.3 and part of human chromosome 22 and thus improved the comparative map with the human genome.

Copyright $@ 2005$ S. Karger AG, Basel
As previously reported (Chantry-Darmon et al., 2003), rabbit is an interesting species both in animal production and medical research but its gene map was poorly developed until recently (Zijlstra et al., 2002; Chantry-Darmon et al., 2003). The production of gene-rich maps is a prerequisite both for high-resolution comparative mapping with man (or other maprich species i.e. mouse, rat, cow, pig) and for projects on the identification of QTLs. Although bi-directional chromosome painting experiments have revealed an overall picture of the extent and distribution of conserved segments between human and rabbit chromosomes (Korstanje et al., 1999), a more detailed comparison would help to add neighbouring markers

C. Chantry-Darmon was supported by the Department of Animal Genetics of INRA and the SYSELAF.

Request reprints from Dr Hélène Hayes

Laboratoire de Génétique biochimique et Cytogénétique, INRA-CRJ

FR-78350 Jouy-en-Josas (France)

telephone: +33(0) 134652673 ; fax: +33 (0) 134652478

e-mail: helene.hayes@jouy.inra.fr in regions of interest. In 2003, we reported a first contribution to the large-scale mapping project in rabbit initiated by the INRA with the localisation of 133 genes by fluorescent in situ hybridisation of gene-containing BAC clones to rabbit chromosomes (Chantry-Darmon et al., 2003). In our continuing goal to develop the comparative map between human and rabbit chromosomes, we have isolated and FISH-mapped rabbit BAC clones for 102 additional genes. Our aim here was to target the search of genes on chromosome bands with no mapped genes to date, based on the existing comparative mapping human/rabbit data.

\section{Materials and methods}

Choice of the genes and primer design, rabbit BAC library screening and sequencing of the $P C R$ products

Previously described procedures (Chantry-Darmon et al., 2003) were used to design the primer sequences and to isolate gene-containing clones from our rabbit BAC library (Rogel-Gaillard et al., 2001) either by a standard PCR-based screening protocol or by hybridisation of high density filters representing the whole library. To check the identity of the sequence inserted in the BAC clones, the PCR product was sequenced and standard nucleotidenucleotide BLASTN analyses were performed.

\begin{tabular}{lll}
\hline KARGER & $\begin{array}{l}\text { Fax +416130612 34 } \\
\text { E-mail karger@karger.ch } \\
\text { www. karger.com }\end{array}$ & ○ 2005 S. Karger AG, Basel \\
1424-8581/05/1112-0134\$22.00/0
\end{tabular}


Probe preparation for fluorescence in situ hybridisation

BAC DNA extracts were prepared according to standard protocols and purified with the S.N.A.P. K1900-01 Miniprep kit (Invitrogen life technologies). DNA was then labelled by nick-translation with biotin-14-dATP (BioNick 18247-015 labelling system, Invitrogen Life Technologies), mixed with $100 \times$ total sonicated herring sperm DNA and $100 \times$ total sonicated rabbit DNA, ethanol precipitated, slightly dried and resuspended in hybridisation buffer.

FISH on R-banded rabbit chromosomes

R-banded chromosome spreads were obtained from rabbit embryo fibroblast cell cultures synchronized with an excess of thymidine and treated with 5-bromodeoxyuridine (BrdU) during the second half of S phase (Hayes et al., 1991). Fluorescent in situ hybridisation, signal detection and R-banding were performed as previously described (Hayes et al., 1992) with 50-100 ng biotin-14-dATP-labelled probe per slide. Before hybridisation to the chromosomes, probes were denatured at $100^{\circ} \mathrm{C}$ for $10 \mathrm{~min}$ and pre-hybridized at $37^{\circ} \mathrm{C}$ for $30-60 \mathrm{~min}$. Slides were examined under a Zeiss Axioplan 2 epifluorescence microscope and the Applied Imaging Cytovision (version 2.7) software was used for image capturing and analysis. Chromosome and band numbering follow Hayes et al. (2002).

\section{Results and discussion}

\section{Choice of genes and recovery of BAC clones}

The 102 new genes localized in this work were chosen based on their position on the human genome i.e. on human chromosome bands not included in our previous report (Chantry-Darmon et al., 2003) or to complete some human chromosome bands containing numerous genes such as $4 \mathrm{q} 13.3$ (SLC4A4 and $G C), 5 \mathrm{q} 33.3$ (ADRA1B), 6q15 (CGA), 9p13.3 (VCP), 17p13.3 (MYH3) and 18q12.1 (MAPRE2). Table 1 presents the chosen genes with their localisation on human chromosomes. The table listing the primer pairs, the species from which the EST originated, GenBank accession numbers and expected size of PCR products is accessible online at http://dga.jouy.inra. fr/lgbc/donnees/pdf/Primer_Information_Rabbit_MS_CGR_ 2005.pdf. As explained in Chantry-Darmon et al. (2003), the availability of many rabbit ESTs and cDNAs in GenBank made it possible to design homologous primers for 93 genes. For the other nine genes, primers were designed from human cDNAs (two) and equine cDNAs (seven). At least one BAC clone was isolated from our rabbit BAC library for each of the 102 genes listed in Table 1 with 28 BAC clones recovered by PCR screening and 74 by hybridisation. In all cases, the sequence of the rabbit PCR product confirmed that the expected gene was contained in the isolated BAC clone.

\section{Localisation of 102 genes on rabbit chromosomes by \\ fluorescent in situ hybridisation}

DNA extracted from each of the 102 rabbit gene-specific BAC clones was biotin-labelled and hybridised to rabbit metaphase chromosome spreads. Clear and consistent hybridisation signals were obtained and images were captured and analysed for at least ten spreads in each case. Results are summarized in Table 1 with those in bold characters indicating localisations obtained with genes from new human chromosomal bands. Indeed, among the 102 newly localized genes on rabbit chromosomes, 74 are positioned to chromosome bands or sub-bands devoid of any mapped gene to date. Figure 1 presents the cur- rent status of the rabbit cytogenetic map constructed in our laboratory, with genes localised during this work indicated in black and those obtained in earlier reports in grey. Newly localized genes are distributed over all the chromosomes except chromosome $\mathrm{Y}$, which still has only $S R Y$ as the single mapped gene. Figure 1 clearly shows that globally we have enriched chromosomes or chromosome arms which were either little (i.e. OCU2, OCU4, OCU7, OCU12, OCU15) or not covered (OCU6q, OCU14p, OCU16p) in our previous work. The p arm of chromosome 15 is still devoid of mapped genes as well as the very small $p$ arms of chromosomes 20 and 21 . For these particular chromosomal regions, it is difficult to focus the search for genes because of the absence of any comparative mapping human/rabbit data. At present, about $43 \%$ of the bands of the rabbit karyotype at the 347-band level (Hayes et al., 2002) carry at least one mapped gene. Most of these bands are R positive, which correlates with the fact that in mammals the $\mathrm{R}$ positive bands are gene-rich (Saccone et al., 1996). However, the band level used for cytogenetic positions of genes on the human genome sequence (Ensembl database http://www.ensembl.org/) is the schematic representation of chromosomes corresponding to approximately 850 bands (ISCN 1981). This is a much higher resolution than that currently used in other species thus more precise comparisons of gene localisations on $\mathrm{R}$ or $\mathrm{G}$ bands between man and another species are not possible. Indeed, an $R$ positive band at the 400-band level may subdivide in two $R$ positive and one $\mathrm{R}$ negative bands at the 850-band level.

\section{Rabbit/human comparative map and detection of a new \\ conserved segment}

We have compared our results (Fig. 1) with the human/rabbit heterologous chromosome painting data reported by Korstanje and colleagues (1999) and we reveal the existence of a previously undetected conserved segment between HSA22 and OCU4. Indeed the localisation of FBXO7 (HSA22q12.3) and DDX17 (HSA22q13.1) genes on rabbit chromosome 4q15.3 shows that a small region of OCU4 band q15.3 is homologous with part of HSA22. This band is a large R positive band in rabbit and we are currently searching for genes in the distal part of HSA22 i.e. on bands $22 \mathrm{q} 13.2$ to $22 \mathrm{q} 13.33$ to determine if this conserved segment extends right to the end of OCU4q15.3. Human/rabbit heterologous chromosome painting had revealed that the long arm of OCU4 is entirely painted by HSA12. Together, with our results, it appears that OCU4q corresponds in fact to a combination of ancestral chromosome forms of HSA12 and 22, an association frequently observed in other species as reviewed by Murphy and colleagues (2001). In addition, our results confirm the conservation between OCU6q and part of HSA7 with the localisation of the EPO gene, between OCU14p and part of HSA3 with the localisation of SLC4A7 gene and between OCU16p and part of HSA10 with the localisation of the $A K R 1 C 3$ gene. These genes are the first to be mapped to these three rabbit chromosome arms and constitute anchors from which we can search for new genes on the corresponding human chromosomes to enrich these rabbit regions. In two cases, our results modify slightly the size of a conserved segment (i) on OCU8 the conserved segment with HSA13 extends to the centromere of OCU8 (localization of the 
Table 1. List of genes mapped in this study, their localisation on human chromosomes, expected localisation in rabbit and FISH localisations. Results in bold characters indicate localisations obtained with genes from human chromosome bands not included in previous studies. Gene symbols follow the HUGO nomenclature (http://www.gene.ucl.ac.uk/nomenclature). For each human chromosome, genes are ordered from the $\mathrm{p}$ telomere to the q telomere according to the Ensembl database (http://www.ensembl.org/).

\begin{tabular}{|c|c|c|c|}
\hline Gene symbol & Gene name & $\begin{array}{l}\text { Human localization } \\
\text { Ensembl Oct } 04\end{array}$ & Rabbit localization \\
\hline PTAFR & platelet-activating factor receptor & $1 \mathrm{p35.3}$ & $13 q 33$ \\
\hline$A G L$ & amylo-1, 6-glucosidase, 4-alpha-glucanotransferase & $1 \mathrm{p} 21.2$ & $13 q 24-q 25$ \\
\hline$C D 1 D$ & CD1D antigen, $d$ polypeptide & $1 \mathrm{q} 23.1$ & $13 \mathrm{q} 21 \mathrm{med}$ \\
\hline CENPF & centromere protein $\mathrm{F}, 350 / 400 \mathrm{ka}$ (mitosin) & $1 q 41$ & 16q16-q21prox \\
\hline LYST (CHS1) & Chediak-Higashi syndrome 1 & $1 q 42.3$ & $16 q 13.3$ \\
\hline CDC42EP3 & CDC42 effector protein (Rho GTPase binding) 3 & $2 \mathrm{p} 22.2$ & $2 q 22.3$ \\
\hline$G G C X$ & gamma-glutamyl carboxylase & $2 \mathrm{p} 11.2$ & $2 q 14$ dist-q15 \\
\hline EIF5B & eukaryotic translation initiation factor $5 \mathrm{~B}$ & $2 q 11.2$ & $2 q 13-q 14$ prox \\
\hline PROC & protein $\mathrm{C}$ (inactivator of coagulation factors Va and VIIIa) & $2 q 14.3$ & $7 q 14$ \\
\hline$L C T$ & lactase & $2 q 21.3$ & 7q15prox \\
\hline CXCR4 & chemokine (C-X-C motif) receptor 4 & $2 q 21.3$ & $7 q 15 p r o x$ \\
\hline ACVR2 & activin A receptor, type II & $2 q 22.3$ & 7q16prox \\
\hline C2orf 25 & chromosome 2 open reading frame 25 & $2 q 23.2$ & $7 q 16 p r o x$ \\
\hline PLA2R1 & phospholipase $\mathrm{A} 2$ receptor $1,180 \mathrm{kDa}$ & $2 q 24.2$ & 7q16dist \\
\hline MYL1 & myosin, light polypeptide 1 , alkali; skeletal, fast & $2 q 34$ & $7 q 23.3-24$ \\
\hline$R A F 1$ & v-raf-1 murine leukemia viral oncogene homolog 1 & $3 \mathrm{p} 25.2$ & 9p13dist (limit p14) \\
\hline$S L C 4 A 7$ & solute carrier family 4 , sodium bicarbonate cotransporter, member 7 & $3 \mathrm{p} 24.1$ & 14p13dist \\
\hline$A C O X 2$ & acyl-Coenzyme A oxidase 2 , branched chain & 3 p14.3 & 9p13prox (limit p12) \\
\hline$S I A H 2$ & seven in absentia homolog 2 & $3 q 25.1$ & $14 q 13$ prox \\
\hline FNDC3B (FAD104) & factor for adipocyte differentiation 104 & $3 q 26.31$ & 14q15dist \\
\hline CLCN2 & chloride channel 2 & $3 q 27.1$ & 14q17dist \\
\hline$L I P H$ & lipase, member $\mathbf{H}$ & $3 q 27.2$ & 14q17dist \\
\hline WDR1 & WD repeat domain 1 & 4p16.1 & $2 \mathrm{p} 25$ \\
\hline$U G D H$ & UDP-glucose dehydrogenase & 4p14 & $2 \mathrm{p} 21.3$ \\
\hline SLC4A4 & solute carrier family 4 , sodium bicarbonate cotransporter, member 4 & $4 \mathrm{q} 13.3$ & $15 \mathrm{q} 23$ dist \\
\hline$G C$ & group-specific component (vitamin D binding protein) & $4 \mathrm{q} 13.3$ & $15 \mathrm{q} 23$ dist \\
\hline PRKG2 & protein kinase, cGMP-dependent, type II & $4 q 21.21$ & 15q23prox \\
\hline$S P P 1$ & secreted phosphoprotein 1 & $4 q 22.1$ & $15 q 22-q 23$ \\
\hline PDLIM5 (LIM) & LIM protein (similar to rat protein kinase C-binding enigma) & $4 q 22.3$ & $15 q 22-q 23$ \\
\hline$A D H 1 B$ & alcohol dehydrogenase IB (class I), beta polypeptide & $4 q 23$ & 15q21dist \\
\hline IL2 & interleukin 2 & $4 q 27$ & $15 q 13$ \\
\hline$U C P 1$ & uncoupling protein 1 (mitochondrial, proton carrier) & $4 q 31.21$ & $15 q 11.5$ \\
\hline$T L R 2$ & toll-like receptor 2 & $4 q 31.3$ & $15 q 11.3$ \\
\hline HAND2 & heart and neural crest derivatives expressed 2 & $4 q 34.1$ & 2p21.1prox \\
\hline$B R I X^{a}$ & BRIX & $5 \mathrm{p} 13.2$ & 11q13prox \\
\hline CKMT2 & creatine kinase, mitochondrial 2 (sarcomeric) & $5 q 14.1$ & 11p14dist \\
\hline TCERG1 & transcription elongation regulator 1 & $5 q 32$ & 3p13dist \\
\hline HAND1 & heart and neural crest derivatives expressed 1 & $5 q 33.2$ & 3p13prox \\
\hline$A D R A 1 B$ & adrenergic, alpha-1B-, receptor & $5 \mathrm{q} 33.3$ & 3 p13prox \\
\hline$R A N B P 9$ & RAN binding protein 9 & $6 \mathrm{p} 23$ & 12 p13 \\
\hline$P R L$ & prolactin & $6 \mathrm{p} 22.3$ & $12 \mathrm{p} 11$ \\
\hline$P G C$ & progastricsin (pepsinogen $C$ ) & $6 \mathrm{p} 21.1$ & $12 q 11.3$ \\
\hline BMP5 & bone morphogenetic protein 5 & $6 \mathrm{p} 12.1$ & $12 q 12 \mathrm{med}$ \\
\hline$C G A$ & glycoprotein hormones, alpha polypeptide & $6 \mathrm{q} 15$ & $12 \mathrm{q} 15$ \\
\hline$R E V 3 L$ & REV3-like, catalytic subunit of DNA polymerase zeta & $6 q 21$ & $12 q 21$ \\
\hline$T$ & $\mathrm{~T}$, brachyury homolog & $6 q 27$ & $12 q 25.3$ dist \\
\hline AOAH & acyloxyacyl hydrolase & $7 \mathrm{p} 14.2$ & 10q14dist \\
\hline EGFR & epidermal growth factor receptor & $7 \mathrm{p} 11.2$ & 10q16dist \\
\hline EPO & erythropoietin & $7 q 22.1$ & $6 q 12 \mathrm{med}$ \\
\hline CALU & calumenin & $7 q 32.1$ & 7 p21prox \\
\hline$C A L D 1$ & caldesmon 1 & $7 q 33$ & 7 p21dist \\
\hline$E R P 70^{a}$ & protein disulfide isomerase related protein & $7 q 36.1$ & 7 p21dist \\
\hline EXT1 & exostoses (multiple) 1 & $8 q 24.11$ & 3q23prox \\
\hline$V C P$ & valosin-containing protein & $9 \mathrm{p} 13.3$ & 1p31prox \\
\hline PSAT1 & phosphoserine aminotransferase 1 & $9 q 21.2$ & $1 \mathrm{p} 12$ \\
\hline$O G N$ & osteoglycin (osteoinductive factor, mimecan) & $9 q 22.31$ & 1p11dist \\
\hline$C E L$ & carboxyl ester lipase (bile salt-stimulated lipase) & $9 q 34.13$ & 1p35dist \\
\hline
\end{tabular}


Table 1 (continued)

\begin{tabular}{|c|c|c|c|}
\hline Gene symbol & Gene name & $\begin{array}{l}\text { Human localization } \\
\text { Ensembl Oct } 04\end{array}$ & Rabbit localization \\
\hline AKR1C1 & aldo-keto reductase family 1 , member $\mathrm{C} 1$ & $10 p 15.1$ & 16p12.1prox \\
\hline$A N X A 8$ & annexin $\mathrm{A8}$ & $10 q 11.22$ & 18q12dist \\
\hline$D D X 21$ & DEAD (Asp-Glu-Ala-Asp) box polypeptide 21 & $10 q 22.1$ & 18q21.3dist \\
\hline LOXL4 & lysyl oxidase-like 4 & $10 q 24.2$ & 18q31dist \\
\hline PNLIP & pancreatic lipase & $10 q 25.3$ & 18q33prox \\
\hline CYP2E1 & cytochrome $\mathbf{P 4 5 0}$, family 2 , subfamily $\mathrm{E}$, polypeptide 1 & $10 q 26.3$ & 18q33dist \\
\hline$C A T$ & catalase & $11 \mathrm{p} 13$ & $1 q 23$ \\
\hline$L P X N$ & leupaxin & $11 q 12.1$ & 1q25dist \\
\hline RPS3 & ribosomal protein $\mathrm{S3}$ & $11 q 13.4$ & $1 q 21.1$ \\
\hline WNT11 & wingless-type MMTV integration site family, member 11 & $11 q 13.5$ & $1 q 21.1$ \\
\hline$T Y R$ & tyrosinase (oculocutaneous albinism IA) & $11 q 14.3$ & 1q14-q15 \\
\hline$M M P 1$ & matrix metalloproteinase 1 (interstitial collagenase) & $11 q 22.2$ & $1 q 14$ \\
\hline$S L N$ & sarcolipin & $11 q 22.3$ & $1 q 14$ \\
\hline HSPA8 & heat shock 70kDa protein 8 & $11 q 24.1$ & 1q12.3prox \\
\hline OLRI & oxidised low density lipoprotein (lectin-like) receptor 1 & $12 \mathrm{p} 13.2$ & $8 p 12.3$ \\
\hline EMP1 & epithelial membrane protein 1 & $12 \mathrm{p} 13.1$ & 8p12.3dist \\
\hline KRT3 & keratin 3 & $12 q 13.13$ & 4q11prox \\
\hline KRT18 & keratin 18 & $12 q 13.13$ & 4q11prox \\
\hline$L U M$ & lumican & $12 q 21.33$ & $4 q 15.1$ \\
\hline CRYL1 & crystallin, lambda 1 & $13 q 12.11$ & $8 q 11$ \\
\hline$A T P 12 A$ & ATPase, $\mathrm{H}+/ \mathrm{K}+$ transporting, nongastric, alpha polypeptide & $13 q 12.12$ & $8 q 11$ \\
\hline TPT1 & tumor protein, translationally-controlled 1 & $13 q 14.13$ & $8 q 13.3-q 21$ \\
\hline$K L F 5$ & Kruppel-like factor 5 & $13 q 22.1$ & $8 q 22$ prox \\
\hline $\mathrm{COCH}$ & coagulation factor $\mathrm{C}$ homolog, cochlin & $14 q 12$ & 17q21dist \\
\hline HIF1A & hypoxia-inducible factor 1 , alpha subunit & $14 q 23.2$ & $20 q 12.1$ \\
\hline CYP19A1 & cytochrome P450, family 19, subfamily A, polypeptide 1 & $15 q 21.2$ & 17q13prox \\
\hline MYO5A & myosin VA (heavy polypeptide 12, myoxin) & $15 q 21.2$ & 17q13prox \\
\hline DPEP1 & dipeptidase 1 & $16 q 24.3$ & 5q16dist \\
\hline MYH3 & myosin, heavy polypeptide 3 , skeletal muscle, embryonic & $17 \mathrm{p} 13.1$ & $19 \mathrm{q} 12.3$ prox \\
\hline ТОВ1 & transducer of ERBB2, 1 & $17 q 21.33$ & 19q21prox \\
\hline $\operatorname{MRCL} 3^{a}$ & myosin regulatory light chain MRCL3 & $18 p 11.31$ & $9 q 13$ \\
\hline MAPRE2 & microtubule-associated protein, RP/EB family, member 2 & $18 \mathrm{q} 12.1$ & $9 q 14.2$ \\
\hline ELAC1 & elaC homolog 1 & $18 q 21.1$ & 9q15.1 \\
\hline$G P I$ & glucose phosphate isomerase & $19 q 13.11$ & 5p12prox \\
\hline CST3 & cystatin C (amyloid angiopathy and cerebral hemorrhage) & 20p11.21 & $4 p 11$ \\
\hline$B C L 2 L 1$ & BCL2-like 1 & $20 q 11.21$ & 4p13med \\
\hline NCOA6 & nuclear receptor coactivator 6 & $20 q 11.22$ & 4p13dist \\
\hline GSS & glutathione synthetase & $20 q 11.22$ & 4p13dist \\
\hline IGLLI & immunoglobulin lambda-like polypeptide 1 & $22 q 11.23$ & 21q12prox \\
\hline $\mathrm{FBXO7}$ & F-box protein 7 & $22 q 12.3$ & 4q15.3prox \\
\hline DDX17 & DEAD (Asp-Glu-Ala-Asp) box polypeptide 17 & $22 q 13.1$ & 4q15.3prox \\
\hline$D D X 3 X$ & DEAD (Asp-Glu-Ala-Asp) box polypeptide 3, X-linked & Xp11.4 & Xp13dist \\
\hline$R G N$ & regucalcin (senescence marker protein-30) & Xp11.3 & Xp11 \\
\hline RPS4X & ribosomal protein $\mathrm{S} 4, \mathrm{X}$-linked & Xq13.1 & $\mathrm{Xq12}$ \\
\hline$S L C 25 A 5$ & solute carrier family 25 , member 5 & $\mathrm{Xq24}$ & Xq21.1 \\
\hline
\end{tabular}

$A T P 12 A$ and $C R Y L 1$ genes) and thus covers the whole of its long arm and (ii) on OCU16, the conservation with HSA10 includes the first band of the long arm of OCU16 while in Korstanje et al. (1999) it was restricted to the short arm only (localization of ITIH2, previous report Chantry-Darmon et al.,
2003). Finally, the comparative human/rabbit cytogenetic map confirms all the painting data obtained by Korstanje and colleagues (1999), including the few readjustments previously discussed and concerning OCU6, 10 and 11 (Zijlstra et al., 2002 and Hayes et al., 2002). 


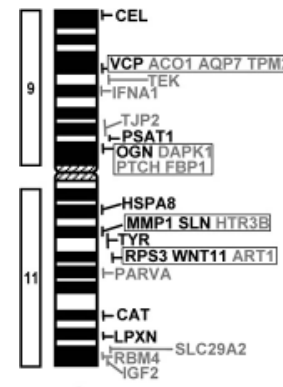

1

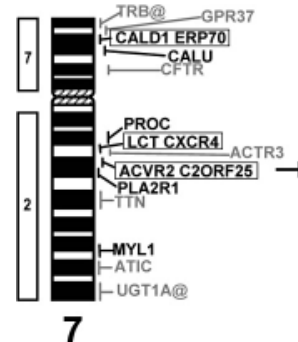

7

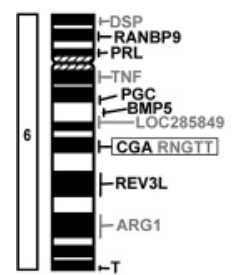

12

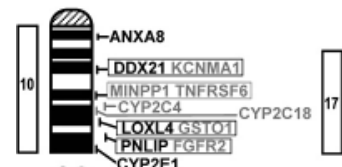

18

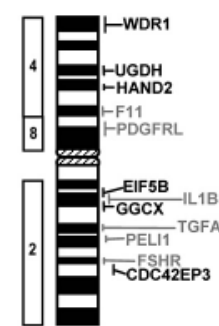

2

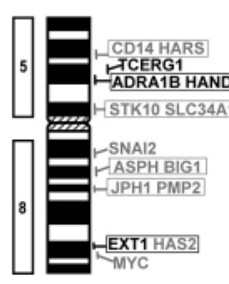

3

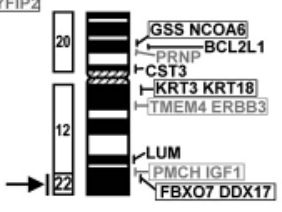

4

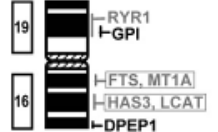

5

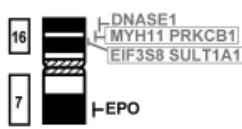

6
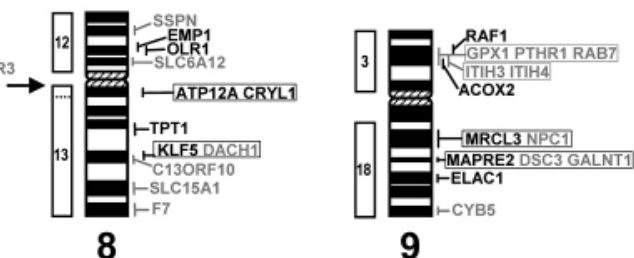

9
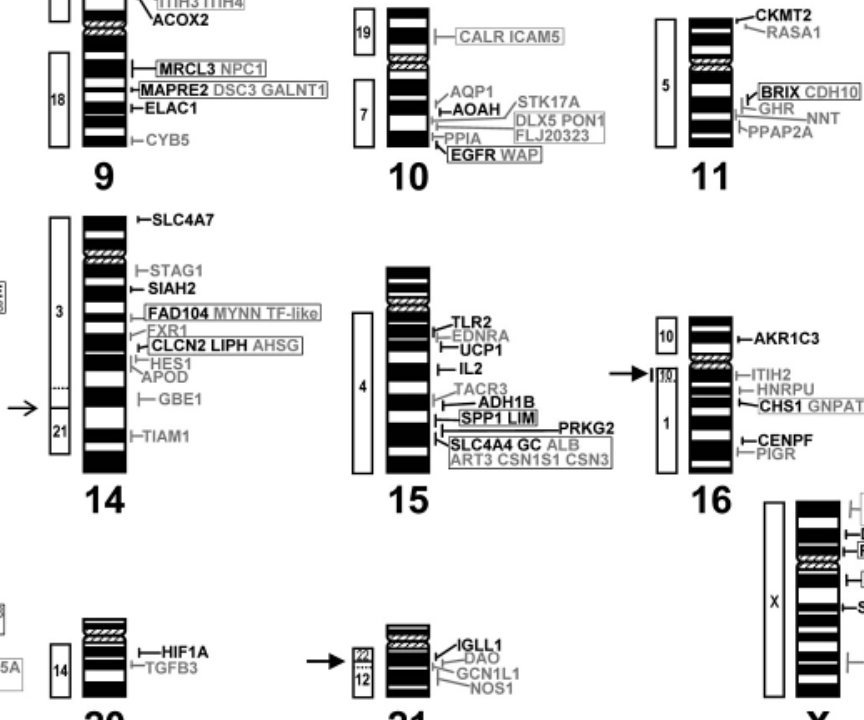

20

13
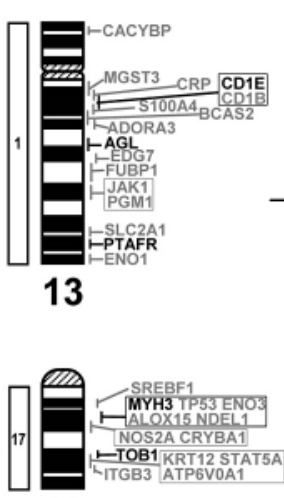

19

Fig. 1. Current rabbit cytogenetic map in our laboratory. The 102 newly localised genes are indicated in black characters on the right of each ideogram while previously mapped genes to R-banded chromosomes are given in grey (Martin-DeLeon et al., 2001; Hayes et al., 2002; Pauloin et al., 2002; Chantry-Darmon et al., 2003). Blocks on the left of each ideogram represent the chromosome correspondences with human chromosomes previously reported by Korstanje et al. (1999). Big arrows with vertical bars indicate a

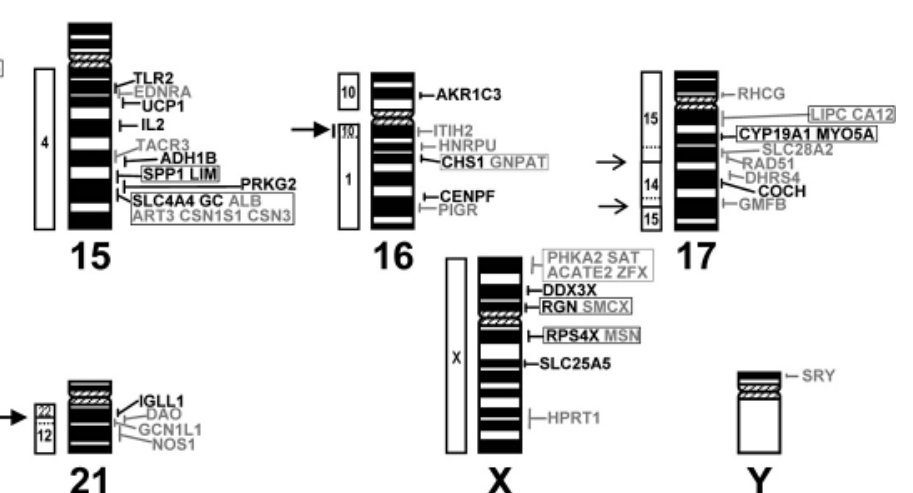

newly detected conserved segment between OCU4 and HSA22 and an extension of the conserved segment between OCU16 and HSA10 to the long arm of OCU16. Big arrows next to OCU8 and OCU21 denote slight modifications in the extension (dotted lines correspond to the previous limits reported by Korstanje et al., 1999) of conserved segments with the human genome (see text). The small arrows next to OCU14 and OCU17 indicate previously reported modifications (Chantry-Darmon et al., 2003).
With the growing number of genes mapped to bands and sub-bands of rabbit chromosomes and although the order of genes between rabbit and human chromosomes appears to be well conserved, it is possible to detect small inversions and rearrangements. In some cases, the series of genes involved include a centromere on the human chromosome while they are situated on a single chromosome arm in rabbit. For example, CDC42EP3 (HSA2p22.2), FSHR (HSA2p16.3), PELI1 (HSA2p14), TGFA (HSA2p13.3), GGCX (HSA2p11.2), cen, EIF5B (HSA2q11.2) and IL1B (HSA2q13) are positioned in the following order along the long arm of rabbit chromosome 2 : EIF5B, IL1B, GGCX, TGFA, PELI1, FHSR and CDC42EP3, which can be explained by an inversion of the segment containing EIF5B and IL1B. The same situation is observed on human chromosome segment $11 \mathrm{p} 15.4$ (ART1)-11q13.2 (RBM4) versus rabbit chromosome segment $1 \mathrm{q} 21.1 \rightarrow \mathrm{q} 21.2$ (ART1)1q27med (RBM4) or human chromosome segment $9 \mathrm{p} 21.3$ (IFNA1)-9q22.32 (PTCH) versus rabbit chromosome segment $1 \mathrm{p} 23$ (IFNA1)-1p11dist (PTCH). Other single inversions are sufficient to restore the gene order between ACTR3-PROC$L C T-C X C R 4$ on HSA2q and (LCT; CXCR4)-ACTR3-PROC on OCU7q or between $D A O-N O S 1-G C N 1 L 1$ on HSA12q and $D A O-G C N 1 L 1-N O S 1$ on OCU21q. Finally, complex rearrangements involving two successive or a segment transposition are necessary to explain differences between HSA7p21.3 $\rightarrow$ p11.2 and OCU10 or HSA7q31.2 $\rightarrow$ q36.1 and OCU7. However, it is clear that many more genes need to be mapped on rabbit chromosomes using high-resolution techniques such as 
radiation hybrid mapping or even better genome sequencing, to analyse precisely the differences in gene order and organisation between the human and rabbit genomes.

Since the beginning of the INRA project on the rabbit map in 2002, we have increased eight-fold the number of precisely localised genes. This data has enabled us to produce directly an integrated cytogenetic and genetic map in rabbit using microsatellite markers isolated from anchored gene-containing BAC clones (in preparation) and to assemble a more precise comparative map, which in turn will speed up the construction of the genetic map.

\section{References}

Chantry-Darmon C, Rogel-Gaillard C, Bertaud M, Urien C, Perrocheau M, Chardon P, Hayes H: 133 new gene localizations on the rabbit cytogenetic map. Cytogenet Genome Res 103:192-201 (2003).

Hayes H, Petit E, Dutrillaux B: Comparison of RBGbanded karyotypes of cattle, sheep and goats. Cytogenet Cell Genet 57:51-55 (1991).

- Hayes H, Petit E, Lemieux N, Dutrillaux B: Chromosomal localization of the ovine beta-casein gene by non-isotopic in situ hybridization and R-banding. Cytogenet Cell Genet 61:286-288 (1992).

Hayes H, Rogel-Gaillard C, Zijlstra C, de Haan NA, Urien C, Bourgeaux N, Bertaud M, Bosma AA: Establishment of an R-banded rabbit karyotype nomenclature by FISH localization of 23 chromosome-specific genes on both G- and R-banded chromosomes. Cytogenet Genome Res 98:199205 (2002)
ISCN (1981): An international system for human cytogenetic nomenclature. High resolution banding: Birth defects. Cytogenet Cell Genet 31:1-23 (1981).

Korstanje R, O'Brien PCM, Yang F, Rens W, Bosma AA, van Lith HA, van Zutphen LFM, FergusonSmith MA: Complete homology maps of rabbit (Oryctolagus cuniculus) and human by reciprocal chromosome painting. Cytogenet Cell Genet 86: 317-322 (1999).

Martin-DeLeon PA, Piumi F, Canaff L, Rogel-Gaillard C, Hendy GN: Assignment of the parathyroid hormone/parathyroid hormone-related peptide receptor (PTHR I) to rabbit chromosome band $9 \mathrm{p} 14 \rightarrow$ p13 by fluorescence in situ hybridization. Cytogenet Cell Genet 94:90-91 (2001).

Murphy WJ, Stanyon R, O'Brien SJ: Evolution of mammalian genome organisation inferred from comparative mapping. Genome Biology 2:1-8 (2001).
Pauloin A, Rogel-Gaillard C, Piumi F, Hayes H, Fontaine ML, Chanat E, Chardon P, Devinoy E: Structure of the rabbit alphas1- and beta-casein gene cluster, assignment to chromosome 15 and expression of the alphas1-casein gene in HC11 cells. Gene 283:155-162 (2002)

Rogel-Gaillard C, Piumi F, Billault A, Bourgeaux N Save JC, Urien C, Salmon J, Chardon P: Construction of a rabbit bacterial artificial chromosome (BAC) library: application to the mapping of the major histocompatibility complex to position 12q1.1. Mamm Genome 12:253-255 (2001).

Saccone S, Caccio S, Kusuda J, Andreozzi L, Bernardi $\mathrm{G}$ : Identification of the gene-richest bands in human chromosomes. Gene 174:85-94 (1996).

Zijlstra C, de Haan NA, Korstanje R, Rogel-Gaillard C, Piumi F, van Lith HA, van Zutphen LFM, Bosma AA: Fourteen chromosomal localisations and an update of the cytogenetic map of the rabbit. Cytogenet Genome Res 97:191-199 (2002). 